\title{
The Expanding Universe of Noncoding RNAs
}

\author{
G.J. Hannon, * F.V. Rivas, * E.P. Murchison,* and J.A. Steitz ${ }^{\dagger}$ \\ *Watson School of Biological Sciences, Howard Hughes Medical Institute, Cold Spring Harbor Laboratory, Cold \\ Spring Harbor, New York 11724; 'Department of Molecular Biophysics and Biochemistry, Howard Hughes \\ Medical Institute, Yale University, New Haven, Connecticut 06536
}

\begin{abstract}
The 71st Cold Spring Harbor Symposium on Quantitative Biology celebrated the numerous and expanding roles of regulatory RNAs in systems ranging from bacteria to mammals. It was clearly evident that noncoding RNAs are undergoing a renaissance, with reports of their involvement in nearly every cellular process. Previously known classes of longer noncoding RNAs were shown to function by every possible means - acting catalytically, sensing physiological states through adoption of complex secondary and tertiary structures, or using their primary sequences for recognition of target sites. The many recently discovered classes of small noncoding RNAs, generally less than 35 nucleotides in length, most often exert their effects by guiding regulatory complexes to targets via base-pairing. With the ability to analyze the RNA products of the genome in ever greater depth, it has become clear that the universe of noncoding RNAs may extend far beyond the boundaries we had previously imagined. Thus, as much as the Symposium highlighted exciting progress in the field, it also revealed how much farther we must go to understand fully the biological impact of noncoding RNAs.
\end{abstract}

It has become customary in Summaries of Cold Spring Harbor Symposia to quote Jacob and Monod (1961). Indeed, hardly any aspect of gene expression escaped mention in their classic paper entitled "Genetic Regulatory Mechanisms in the Synthesis of Proteins" published in 1961 in the Journal of Molecular Biology. The possibility of a regulatory role for RNA was no exception. In the schemes presented in Figure 6 for the control of protein synthesis, not only the Messengers but also the Repressor were modeled as RNA, accompanied by the following explanations:

(1) 'The specific 'repressor' (RNA?), acting with a given operator, is synthesized by a regulator gene."

(2) "The chemical identification of the repressor as an RNA fraction is a logical assumption based only on the negative evidence which indicates that it is not a protein."

The notion that RNA might use its base-pairing potential to regulate the activity of DNA was irresistible at the time, and the lasting appeal of this idea appears ever more justified with each passing year. Even though the lac repressor turned out to be a protein, the roster of noncoding RNAs (ncRNAs) presaged by Jacob and Monod has grown steadily. We now appreciate that ncRNAs are involved in the control of gene expression, as well as many other aspects of cellular metabolism. Beginning with the basic triumvirate of messenger RNA (mRNA), ribosomal RNA (rRNA), and transfer RNA (tRNA), new classes of RNA have materialized every few years.

The discovery of introns in 1977 seeded the realization that small nuclear RNAs (snRNAs) are building blocks of the spliceosome. snRNAs use base-pairing to recognize critical landmarks within the intron undergoing excision. Small nucleolar RNAs (snoRNAs) were later found to use sequence complementarity to guide nucleotide modification of conserved regions within eukaryotic rRNAs. This phenomenon is not restricted to eukaryotes, as snoRNAs have analogs even in Archaea. Additionally, the discovery that the RNA component of telomerase dictates the sequence added to the ends of the DNA of most eukaryotic chromosomes expanded the mechanisms by which ncRNAs act.

The demonstration of RNA catalysis in the 1980s, initially in self-splicing introns and in RNA cleavage, proved that RNA molecules - by assuming defined secondary and tertiary structures - are not confined to regulatory and structural roles in cellular machines. These findings underscored the centrality of RNA in the evolution of life and culminated with the revelation from structural studies that the ribosome is a ribozyme (Nissen et al. 2000).

The recent explosion both in the roster of ncRNAs and in our appreciation of the multifaceted regulatory potential of RNA constitutes another RNA revolution. It began in 1998, when double-stranded (ds)RNA was identified as the active principle in gene silencing in experiments conducted in Caenorhabditis elegans by Fire and Mello (Fire et al. 1998) and in Trypanosoma brucei by Ullu and Tschudi (Ngo et al. 1998). Baulcombe's laboratory then uncovered the coincident existence of short ( 25 nucleotide) RNAs in plant cells undergoing posttranscriptional gene silencing (PTGS) as a result of the introduction of exogenous genes or viral infection (Hamilton and Baulcombe 1999). Links between PTGS in plants and RNA interference (RNAi) in animals were forged by the discovery of a conserved enzymatic machinery that produces small RNAs (Hammond et al. 2000; Zamore et al. 2000; Bernstein et 
al. 2001; Hutvagner et al. 2001) and a conserved core of the effector complexes (called RISC, for RNA-induced silencing complexes) that uses small RNAs to guide silencing of target genes (Hammond et al. 2000, 2001; Hutvagner and Zamore 2002; Martinez et al. 2002). These cellular components could exist simply to lie in wait for infecting viruses that produce dsRNAs as part of their replication cycle; indeed, small RNA pathways are critical to viral resistance in plants. However, it seemed more likely that such a flexible and adaptive machinery would have evolved to regulate naturally occurring, endogenous substrates. Already in 1993, the Ambrose and Ruvkun labs had characterized a 21nucleotide RNA that blocks translation of the C. elegans lin-14 mRNA via complementarity in the 3'UTR (Lee et al. 1993; Wightman et al. 1993). This and let-7, the other "small temporal RNA," were linked to the RNAi pathway through genetic analysis of Dicer mutants (Grishok et al. 2001; Hutvagner et al. 2001; Ketting et al. 2001; Knight and Bass 2001), opening the door to the documentation of hundreds of additional novel tiny RNAs (microRNAs) present in Drosophila, C. elegans, and human cells by the Tuschl, Bartel, and Ambros labs (Lau et al. 2001; Lagos-Quintana et al. 2001; Lee and Ambros 2001).

The last several years have taught us that the RNAi pathway can regulate gene expression in an astonishing variety of ways. Genes can be silenced by modification of chromatin structure, by mRNA cleavage, and by affecting mRNA localization, polyadenylation, and productive translation (Hannon 2002; Grewal and Moazed 2003; Bartel 2004; Valencia-Sanchez et al. 2006). Small RNAs can even accomplish the ultimate form of gene silencing, marking sequences for expulsion from the genome by programmed DNA elimination (Mochizuki et al. 2002; Matzke and Birchler 2005). Clearly, gene regulation by small RNAs that are processed from dsRNA precursors by Dicer comprises a rich and varied collection of biological pathways. However, it is also evident that our explorations so far have reached only the nearest and most easily observed parts of the ncRNA universe. As the power of our observational tools increases, we begin to see glimmers of a ncRNA world that is as beautiful and complex as it is daunting and difficult to fully comprehend.

The Cold Spring Harbor Symposium on "Regulatory RNAs" was both a celebration of the richness and breadth of ncRNA function and an indicator of the many vistas that remain to be explored. It gathered scientists from a number of subfields, previously divided on the basis of organism studied, cellular process, or experimental approach. The purpose of this summary is to provide a framework for bringing together what has been learned in past decades about larger ncRNAs (generally in the size range of 60 to several hundred nucleotides) in cells from bacteria to man with the current intense focus on small RNAs (usually only 20-30 nucleotides long). Since all cellular RNA molecules exist in complexes with protein(s), deciphering how these partners contribute to the function of small RNAs is also integral to understanding their biological roles.

\section{TODAY'S TALLY OF NCRNAS}

Genome studies set the stage for thinking about the immense potential for the involvement of ncRNAs in regulating all aspects of genome organization, cellular metabolism, and organismal development. An introduction to the tremendous potential complexity of ncRNAs in eukaryotes came from Tom Gingeras (Carninci et al. 2005; Manak et al. 2006) and Mike Snyder (Bertone et al. 2004; Emanuelsson et al. 2006). Their studies collectively indicate that the transcriptome is much more extensive than previously thought. Even polling only the nonrepetitive portions of the genome in just a few cell types or developmental stages indicates that more than $85 \%$ of DNA sequences are used as templates for RNA production in mammals and flies. In fact, as many as 400,000 sites in the human genome may give rise to RNAs 20-200 nucleotides long! Additionally, many unannotated, transcribed sequences represent far distant $5^{\prime}$ exons of known protein-coding genes, which are used when those genes are expressed in developmentally or cell-type-specific ways. Nick Proudfoot's consideration of intragenic ncRNA regions focused attention on the possibility of cotranscriptional RNA turnover and the question of how the loop conformations of active genes may affect the fate of transcripts (West et al. 2004, 2006; Haussecker and Proudfoot 2005; Dye et al. 2006; Gromak et al. 2006).

Alex Hüttenhofer pointed out that the fraction of noncoding DNA increases across phylogeny (Hüttenhofer and Schattner 2006). In bacteria, approximately 100 small RNAs are known so far. Although this number will undoubtedly increase somewhat, it may reflect the fact that a smaller percentage of the bacterial genome, roughly $10 \%$, constitutes noncoding regions, whereas for a typical mammalian genome, as much as $98 \%$ of the DNA may be considered non-protein-encoding.

\section{Key emerging questions:}

- How many functional classes do ncRNAs represent?

- What are their biological roles?

- What will we find in more comprehensive cell-type and tissue surveys?

- Do ncRNAs dominate the regulatory circuitry of the cell?

\section{REGULATORY RNA MOLECULES AND SEQUENCES IN BACTERIA}

Susan Gottesman introduced small RNAs in bacteria with the provocative claim, "Anything DNA can do, RNA can do better!" She categorized the known instances of regulation via RNA in bacteria as (1) interactions of mRNA $5^{\prime}$ leaders with metabolites or cellular milieu (such as temperature) to modify transcription or translation, (2) interactions of small RNAs with regulatory proteins to modify their activities, and (3) interactions 
between regulatory RNAs and mRNAs to positively or negatively affect transcription, stability, or translation (Gottesman 2005; Majdalani et al. 2005). Pairing between a regulatory RNA and its target in vivo is often facilitated by Hfq, the bacterial homolog of the Sm proteins that comprise the core of spliceosomal snRNPs (Moller et al. 2002; Zhang et al. 2002). Control of synthesis of a small RNA can be the primary regulatory step, as in the case of stress responses, including the presence of unfolded proteins in the periplasm. Gigi Storz emphasized that not only the $5^{\prime}$ leaders but also the 3'UTRs of mRNAs can provide recognition sites for small RNAs and discussed the importance of changes in RNA processing and stability resulting from mRNA-small RNA interactions (Storz et al. 2004, 2005).

We have long realized that alternative mRNA secondary structures induced by the passage of ribosomes can have diverse consequences. These include regulating transcription termination in the Trp and other amino acid biosynthetic operons, as well as inducing erythromycin resistance by relieving the sequestration of a ribosome-binding site (Weisblum 1995; Gollnick et al. 2005). However, additional novel examples, dubbed "riboswitches," have recently emerged (Winkler 2005; Gilbert and Batey 2006; Grundy and Henkin 2006). Tina Henkin reviewed the evidence for the T-box riboswitch that uncharged (but not charged) tRNA interacts with multiple sites in the $5^{\prime}$ leader RNA to tighten its structural fold, facilitating the formation of an antiterminator stem that allows transcriptional readthrough (Nelson et al. 2006). Smaller currently known ligands for riboswitches range in size from metabolites (such as amino acids, vitamins, and nucleobases) to $\mathrm{Mg}^{++}$, recently identified by Eduardo Groisman as the ligand that alters transcription of the 5'UTR of the mgtA gene of Salmonella (Cromie et al. 2006). Sequence analyses of multiple riboswitches have confirmed the generality of a two-domain structure - one for ligand binding called the aptamer domain and the second referred to as the platform or expression domain. A novel type of platform domain, a self-cleaving ribozyme, was described by Wade Winkler in the $5^{\prime}$ leader of the glmS transcript in Bacillus.
The activity of riboswitches is generally achieved by their adopting complex secondary and tertiary structures. Sean Eddy reviewed the special challenges posed when attempting to predict and align RNA secondary structures (Dowell and Eddy 2006). Progress with a new algorithm borrowed from computational linguistics is encouraging.

Multiple insights were provided by the high-resolution 3D structures of the purine and SAM-I riboswitches bound to their cognate ligands, as presented by Rob Batey (Montange and Batey 2006). Although distinct, the structures reveal several common features: The RNA aptamer domains exploit almost every feature of their ligand to achieve extraordinary binding specificity; complex tertiary structures establish the binding pocket; and ligand binding acts to stabilize a helix that communicates to the expression domain (forcing it to assume one of two mutually exclusive alternative structures in the case of the SAM-I riboswitch).

\section{Key emerging questions:}

- Are there additional regulatory roles for small RNAs in bacteria?

- How widespread in biology are riboswitches?

- How many biological processes are regulated in this manner?

- Will all riboswitches act similarly to those already identified?

- How might we efficiently search for such regulatory RNAs and sequences?

\section{NCRNAS PARTICIPATE IN ALMOST EVERY FUNCTION OF THE CELL NUCLEUS}

The most famous ncRNAs of the nuclear compartment are the snRNA components of the spliceosome. The spliceosome comes in two flavors, the major (or U2-type) and the minor (U12-type), which has four distinct snRNAs, in the cells of higher plants and animals (Table 1) (Patel

Table 1. Noncoding Nuclear RNAs of Animals/Plants

\begin{tabular}{lll}
\hline & Location & Function \\
\hline U1, U2, U4, U5, U6 snRNAs & nucleoplasm & $\begin{array}{l}\text { splicing: major } \\
\text { minor } \\
\text { U11, U12, U4 atac, U6 }{ }_{\text {atac }} \text { snRNAs }\end{array}$ \\
SL RNAs & & $\begin{array}{c}\text { trans } \\
\text { histone mRNA 3' ends }\end{array}$ \\
U7 snRNA & Cajal bodies & $2^{\prime}$-O-methylation \\
Box C/D snoscaRNAs & nucleoli/Cajal bodies & pseudouridylation \\
Box H/ACA snoscaRNAs & nucleoli/Cajal bodies & telomere regulation \\
Telomerase & Cajal bodies & tRNA processing \\
RNase P & nucleoplasm & transcription regulation \\
7SK, murine B2 & nucleoplasm & dosage compensation \\
Xist, Tsix, roX $X$ RAs & nucleoplasm & transcriptional silencing \\
siRNAs in RITS (plants/fungi) & chromatin & DNA elimination \\
scnRNAs (ciliates) & macronucleus &
\end{tabular}


and Steitz 2003; Will and Luhrmann 2005). Some organisms (such as nematodes and trypanosomatids) trans splice, joining two distinct RNAs and releasing a Ybranched RNA comprising two intronic fragments. Although splicing itself is highly regulated (more than $70 \%$ of human gene transcripts are currently estimated to be alternatively spliced), it is not the RNA components of the spliceosome that change but the binding of proteins to the pre-mRNA that modulates spliceosome assembly. Bob Darnell used studies of the neuron-specific RNAbinding protein Nova to illustrate how a combination of biochemical, genetic, and bioinformatic tools have not only elucidated the mechanism of alternative splicing, but also identified the pre-mRNAs bound by Nova (Ule et al. 2006). The unexpected outcome is a remarkable coherence in the nature of the RNAs targeted by Nova-all encode proteins related to synapse formation or function!

The unusual role of a box C/D snoRNA (Table 1) as a splicing regulator was related by Stefan Stamm; HBII52 snoRNA, which is not expressed in patients with Prader-Willi syndrome, base-pairs to a splicing silencer in the serotonin receptor pre-mRNA, resulting in alternative exon usage (Kishore and Stamm 2006). Gideon Dreyfuss described how the SMN (survival of motor neurons) complex of proteins, a known mediator of snRNP assembly, identifies snRNAs by the proximity of the Sm-binding site to the $3^{\prime}$ end and thereby discriminates against other cellular RNA targets, eliminating illicit RNA-protein interactions (Golembe et al. 2005; Battle et al. 2006).

A novel role for 7SK, an abundant nuclear RNA previously implicated in the control of transcription elongation by sequestering (in cooperation with the HEXIM1 protein) $\mathrm{P}-\mathrm{TEFb}$ into a kinase-inactive complex (Yik et al. 2003), was revealed by Qiang Zhou. He reported that $7 \mathrm{SK}$ also binds and suppresses the cytosine deaminase activity of APOBEC 3C, perhaps by inducing its sequestration in the nucleolus. The theme of RNA sequestration in the nuclear compartment as a means of regulating gene expression was echoed by David Spector, who showed that the CTN-RNA, an inosine-containing RNA that is normally retained in the nucleus, is cleaved within its 3'UTR following cellular stress. It is then transported to the cytoplasm and translated into protein (Prasanth et al. 2005). Further bioinformatic analyses have identified other nuclear retained RNAs, suggesting that we have much to understand about the function of nuclear retained stable RNA transcripts.

Versatility in the function of box H/ACA RNAs (Table 1) is also evident. Among the several hundred different H/ACA RNAs in human cells are not only pseudouridylation-guide RNAs that reside in the nucleolus (to modify rRNA) or Cajal bodies (to modify snRNAs), but also the RNA component of telomerase (Meier 2005, 2006). Although discussing different aspects of box H/ACA RNP assembly, both Tamás Kiss and Michael Terns commented on the regulated intranuclear trafficking of telomerase RNA during the cell cycle and the idea that Cajal bodies may deliver telomerase to only a fraction of telomeres during each $\mathrm{S}$ phase (Jady et al. 2006; Tomlinson et al. 2006).
Tom Cech brought a new perspective to the structural categorization of small RNPs based on studies of yeast telomerase. Rather than possessing a specific structure determined in large part by RNA (e.g., the ribosome) or by proteins (e.g., snRNPs), the yeast telomerase RNA serves as a flexible scaffold that tethers essential proteins together (Zappulla and Cech 2004; Zappulla et al. 2005). Liz Blackburn reported the effects of telomerase RNA knockdown or overexpression on the growth characteristics and metastatic potential of human cancer cells (Nosrati et al. 2004; Li et al. 2005). Carol Greider discussed the unanticipated generational effects of heterozygosity at the telomerase RNA locus in mice (Hao et al. 2005). The data suggest that half the level of telomerase RNA leads to telomere shortening and stem cell loss that increases in severity with each generation. Even though progeny from matings of telomerase heterozygotes may possess a wild-type genome, one generation in this wildtype state is not enough to restore telomere length, leading to "occult genetic disease!"

Large ncRNAs underlie dosage compensation in both mammals and fruit flies (Deng and Meller 2006; Heard and Disteche 2006; Rea and Akhtar 2006). In Drosophila, the MSL complex of five proteins in conjunction with two functionally redundant roX (RNA on X) RNAs binds and upregulates transcription of the single male $\mathrm{X}$ chromosome, apparently by altering chromatin structure. Mitzi Kuroda presented results from chromatin immunoprecipitation experiments that reveal preferential binding to the middle and $3^{\prime}$ ends of actively transcribed genes (Alekseyenko et al. 2006); it makes sense that only active $X$ genes should be upregulated, but neither the specific role of the roX RNAs in this process nor the mechanisms by which MSL complexes recognize and modify chromatin only for the correct gene subset are yet understood. Perhaps, as in the case of the yeast telomerase RNA, roX RNAs act to provide a flexible scaffold that ensures delivery of just the right collection of chromatin-modifying enzymes to their target genes.

In mammals, dosage compensation is achieved by transcriptional silencing of one $\mathrm{X}$ chromosome in female cells. The required $\mathrm{X}$ inactivation center $(X i c)$ contains genes for several large ncRNAs, including Xist (which accumulates on the inactive $\mathrm{X}$ ) and its antisense partner Tsix (Heard and Disteche 2006). Jeannie Lee highlighted recent support for a model that explains the mutually exclusive silencing of one of the two $\mathrm{X}$ chromosomes: Inactivation occurs after transient pairing of the homologous chromosomes via their Xic regions from which they emerge differentially marked (Xu et al. 2006). The requirement for Tsix RNA for pairing suggests that Tsix RNA controls Xist promoter methylation, thereby silencing Xist on the opposite chromosome. Edith Heard presented studies on the mechanism by which Xist might enforce silence. She proposed that RNA polymerase II becomes excluded from an "Xist domain." Exclusion occurs before transcriptional repression of the inactive $\mathrm{X}$, and prior to inactivation, expressed genes are resident at the periphery or outside the Xist domain (Chaumeil et al. 2006). Considered as a whole, the data suggest that Xist RNA participates in the formation of a silent nuclear compartment into which inactivated X-linked genes are recruited. 
Key emerging questions:

- Will many alternative splicing regulators, such as Nova, act on functionally coherent sets of mRNAs?

- Will the assembly of many RNPs be chaperoned by complexes such as SMN?

- Does 7SK have yet other partners and functions than those previously reported?

- Do telomeres send signals to Cajal bodies when they get too short?

- How do roX RNA complexes recognize and activate their targets?

- How can ncRNAs like Xist create silent nuclear compartments?

- Are there other examples of such behavior in which ncRNAs target genes to nuclear substructures?

\section{Roles for ncRNAs in Genome Organization and Heterochromatin Formation}

Heterochromatin has traditionally been thought to be transcriptionally silent. The surprising finding that heterochromatin produces numerous ncRNAs, which are essential to the maintenance of the heterochromatic state, is changing our perception of heterochromatin and challenging the definition of transcriptional "silence."

Richard Jorgensen's studies have revealed a diversity of pathways that lead to RNA-induced epigenetic changes in plants and provide insight into how these integrate across tissues and generations. Genetic requirements for RNA-directed DNA methylation (RdDM) in Arabidopsis are being clarified through the work of Marjori Matzke, Steve Jacobsen, and Craig Pikaard. In addition to a DNA-methyltransferase, RdDM requires several components of the RNAi machinery, including DCL3 and AGO4 (Gendrel and Colot 2005). An important role is emerging for a plantspecific, atypical DNA-dependent RNA polymerase, pol IV, not only in the transcription of heterochromatic loci that serve as silencing triggers, but also downstream, during the deposition of the methyl-cytosine mark (Kanno et al. 2005a, b). Interestingly, subcellular localization studies by Steve Jacobsen and Craig Pikaard show that several steps in the RdDM pathway appear to occur in the Cajal body, implying a similarity between nuclear RISC maturation and other RNP assembly pathways (Li et al. 2006; Pontes et al. 2006).

Studies by Danesh Moazed, Shiv Grewal, and Rob Martienssen have focused on the role of RNA in regulating heterochromatin in the fission yeast Schizosaccharomyces pombe. In contrast to the outdated understanding of heterochromatin as a condensed state refractory to transcription, in $S$. pombe, heterochromatin-embedded "silent" transgenes retain high pol II occupancy and are transcriptionally active. Nascent transcripts from these genes are recognized by small
RNAs resident in a RISC-like complex, RITS (RNAinduced transcriptional silencing), and cleaved co-transcriptionally (Irvine et al. 2006). In fact, the production of RNA from heterochromatic genes is required for the generation of small RNAs and serves as part of a feedforward loop that is required to maintain the heterochromatic state. Thus, heterochromatin must be expressed in order to maintain "silence."

Although the details of the mechanisms by which RNA induces chromatin modifications and DNA methylation remain unclear, a series of experiments by Greg Hannon, Rob Martienssen, and Shiv Grewal have implicated the "slicer" activity of Argonaute (Ago) proteins in this process (Irvine et al. 2006; Qi et al. 2006). Interestingly, whereas Agol slicer activity is absolutely required for heterochromatin maintenance in $S$. pombe, in Arabidopsis only a subset of epigenetically controlled loci are sensitive to the loss of AGO4 cleavage activity while others are not. These seemingly divergent results can be unified by imagining that Argonaute complexes can serve two distinct roles at silenced loci. The first, which requires Argonaute's catalytic potential, is to cleave chromatin-associated nascent transcripts. By analogy with trans-acting siRNA generation pathways in plants, one might imagine that this cleavage triggers the production of small RNAs from the loci. Indeed, loss of small RNAs from target genes is observed upon negation of cleavage potential in both plants and yeast (Irvine et al. 2006; Qi et al. 2006). A second function, which is independent of cleavage, may be to recruit chromatinmodifying complexes that mark target loci by histone methylation. In $S$. pombe at least, such modifications also recruit RITS (Motamedi et al. 2004; Verdel et al. 2004; Buhler et al. 2006), perhaps increasing the local concentration of silencing factors and creating a microdomain that is analogous to the silent domain created by Xist in female mammalian cells.

\section{Key emerging questions:}

- What is the functional definition of heterochromatin?

- How are certain heterochromatic sites selected for small RNA generation in plants and fungi?

- How do RISC and RITS direct histone and DNA modification?

- Do analogous small RNA-directed chromatin modification complexes exist in mammals and, if so, what is their biological function?

\section{NCRNAS IN VIRUS-INFECTED CELLS}

Nearly every regulatory strategy employed by host cells is exploited by viruses, and small RNA pathways are no exception. Table 2 summarizes the current roster of small RNAs found in virus-infected mammalian cells. The large double-stranded DNA genomes of gamma her- 


\section{HANNON ET AL.}

Table 2. Viral Noncoding RNAs in Primates

\begin{tabular}{|c|c|c|}
\hline & Virus & Function \\
\hline VA 1 and 2 RNAs & Adenovirus & inactivate PKR \\
\hline HSUR 1-7 snRNAs & Herpesvirus saimiri & $\begin{array}{l}\text { up-regulation of host genes } \\
\text { involved in T-cell activation }\end{array}$ \\
\hline EBER 1 and 2 snRNAs & Epstein-Barr (EBV) & enhance tumorigenic potential \\
\hline PAN (poly $a$ denylated $n$ uclear) RNA & $\begin{array}{c}\text { Kaposi sarcoma associated } \\
\text { herpesvirus (KSHV) }\end{array}$ & $?$ \\
\hline Virus-encoded microRNAs & $\begin{array}{l}\text { EBV } \\
\text { KSHV } \\
\text { Polyoma virus } \\
\text { SV40 }\end{array}$ & $?$ \\
\hline
\end{tabular}

pesviruses, such as EBV and KSHV, have emerged as the champion microRNA-encoding viral representatives (each with 10-20), although little is yet known about whether these microRNAs target viral or host-cell functions. The long-standing mystery of why a transcript called BART simply turns over in the nucleus of EBVinfected cells was elucidated by Bryan Cullen, who reported that it serves as the precursor for no fewer than 14 microRNAs (Cai et al. 2006). Joan Steitz discussed a larger $(\sim 1 \mathrm{~kb}) \mathrm{KSHV}$ lytic-phase noncoding transcript called PAN, which never leaves the nucleus and has provided insights into a rapid poly(A)-dependent RNA decay pathway that may be part of a nuclear surveillance system in mammalian cells (Conrad et al. 2006).

Don Ganem uncovered the existence of a conserved cluster of SV40 microRNAs. These arise from readthrough transcripts of the late region and induce RISCmediated cleavage of early transcripts. This enables the virus to down-regulate production of $\mathrm{T}$ antigen, an essential early product that would otherwise become a major target of host cytotoxic T lymphocytes (Sullivan et al. 2005). A slightly different scenario was described by Gordon Carmichael for the related polyoma virus. In this case, RNA editing of dsRNA created by hybridization of the poly(A) signals at the $3^{\prime}$ ends of the early and late transcripts suggests an editing-versus-cleavage/polyadenylation model for the switch between early and late gene expression.

In the case of hepatitis $\mathrm{C}$ viral infection of liver cells, Peter Sarnow reported both positive and negative roles for a host cell microRNA (Jopling et al. 2005). miR-122 downregulates the cationic amino acid transporter, CAT-1, by binding its 3'UTR but positively modulates viral RNA replication through complementarity to a site near the $5^{\prime}$ end of the viral genome. Clearly, the latter function is profoundly mysterious, as it cannot yet be linked to any of the mechanisms by which microRNAs are known to operate.

\section{Key emerging questions:}

- Did viral small RNAs evolve independently or were they originally captured from host genomes?

- Do viruses exploit microRNAs for self-regulation (e.g., of latent states) or primarily for regulation of host functions?

- Viruses often make noncanonical use of cellular components. Are microRNAs always used in the conventional way by viruses?

- Does the cellular RNAi machinery ever serve as an antiviral defense in mammals?

\section{SMALL CYTOPLASMIC RNAS OF ANIMALS AND PLANTS}

Both the cytosol and mitochondria harbor ncRNAs whose functions are well delineated (Table 3), in addition to some that have remained enigmatic for decades (e.g., vault RNAs). New insight into the role of Y RNAs, which bind a protein called Ro, was offered by Sandy Wolin. Ro's donut shape (Stein et al. 2005) allows it also to recognize misfolded ncRNAs (such as 5S and U2 snRNAs), but in a way mutually exclusive with Y RNA binding, suggesting that Y RNAs act to regulate Ro's role as part of an RNA quality control pathway in animal cells.

Table 3. Noncoding Cytoplasmic RNAs of Animals and Plants

\begin{tabular}{lll}
\hline & Location & Function \\
\hline Y RNAs & cytosol & regulate Ro function \\
7SL (SRP) & cytosol & protein translocation to ER \\
MRP & mitochondria & DNA replication \\
Editing guide RNAs & mitochondria & U insertion/deletion in trypanosomes \\
Vault RNAs & vaults & $?$ \\
Alu/BC1 transcripts & cytosol & $?$ \\
MicroRNAs & cytosol/P bodies & repression \\
Multiple novel classes & $?$ & $?$ \\
\hline
\end{tabular}




\section{Diversity of Small RNAs}

Deep sequencing technology has recently revealed hidden depths of small RNA diversity in both plants and animals, with several new classes emerging at the meeting. Greg Hannon and David Bartel introduced Piwiinteracting RNAs (piRNAs), a class of small RNAs in the mammalian testes that associate with Argonaute proteins of the Piwi clade (Aravin et al. 2006; Girard et al. 2006; Lau et al. 2006). piRNAs are about 30 nucleotides long, with a very strong propensity for $5^{\prime}$ uracil. Although both their biogenesis and function remain elusive, piRNAs are interestingly derived from discrete genomic loci with profound strand asymmetry. Unlike microRNAs, piRNAs are not conserved, even among mammals. Yet, they are produced from syntenic regions of the mouse, rat, and human genomes.

Phil Zamore presented evidence that Piwi proteins in Drosophila bind repeat-associated RNAs (rasiRNAs) (Vagin et al. 2006). These 24- to 26-nucleotide-long RNAs predominantly target transposons and are biased toward antisense species. Since both piRNAs and rasiRNAs are produced in the germ line, both bind Piwi proteins, and Piwi family proteins are essential for germline integrity in flies and mammals, it is tempting to speculate that the two types of small RNAs are related. However, to date, lack of information concerning the biogenesis of the two small RNA classes and the function of mammalian piRNAs precludes definitive conclusions.

Why piRNAs and rasiRNAs are essential for germ-line integrity remains a mystery. However, Bill Theurkauf suggested that rasiRNAs, at least, have a role in suppressing DNA damage signaling in the germ line (Klattenhoff et al. 2007). He showed that mutations in chk2, a key damage signaling component, could suppress the effects of mutations in a Drosophila Piwi-family gene, Aubergine. This raises the possibility that loss of the rasiRNA pathway affects germ-line integrity by suppressing transposons, whose activity can lead to DNA damage, rather than by regulating gene expression.

David Baulcombe and Greg Hannon provided detailed characterizations of AGO1- and AGO4-bound small RNAs in Arabidopsis (Qi et al. 2006). Although these species were known previously, deep sequencing has allowed a new level of analysis. AGO1 binds mainly 21nucleotide microRNAs, with a number of new candidate plant microRNAs evident in the sequenced collection. AGO4 binds 24-nucleotide RNAs, many of which depend on RNA pol IV activity and correspond to nearly every repetitive and transposable element in the Arabidopsis genome. Superficially, these may be considered analogs of Drosophila rasiRNAs, except that AGO4-bound siRNAs are produced by a Dicer-dependent mechanism whereas rasiRNAs seem to be Dicer-independent and may not even be derived from dsRNA precursors.

Detailed analyses of small RNA sequences in C. elegans were described by Dave Bartel. Along with numerous microRNAs and endogenous siRNAs, a new class of abundant 21-nucleotide molecules emerged (Ruby et al. 2006). They are characterized by a prominent $5^{\prime}-U$ bias and by the presence of a highly characteristic sequence motif about $42 \mathrm{bp}$ upstream of the start of the small RNA. 21U RNAs are not obviously produced by processing dsRNA precursors but instead may represent discrete transcription products from loci that cluster in the genome.

Recent advances in our understanding of other elusive small RNA classes, including plant trans-acting siRNAs (tasiRNAs), Tetrahymena thermophila scnRNAs, and $C$. elegans secondary siRNAs, were discussed in less detail in both posters and talks at the meeting.

Most deep-sequencing studies carried out to date have been specifically designed to identify small RNAs with characteristics of siRNAs and microRNAs. With a view toward genome-wide studies of RNA expression, described above, it is clear that there may still be many types of small RNAs that remain to be uncovered.

\section{Key emerging questions:}

- How many discrete classes of small RNAs exist?

- How are piRNAs and rasiRNAs produced?

- What are the functions of mammalian piRNAs and C. elegans $21 \mathrm{U}$ RNAs?

- How does biogenesis of tasiRNAs and heterochromatic siRNAs in plants and fungi relate to secondary siRNA production in worms?

\section{MicroRNA Biogenesis}

Although mechanisms that produce some of the newer classes of small RNAs remain a complete mystery, pathways leading to the production of siRNAs and microRNAs have come into increasingly sharp focus. MicroRNAs are processed from longer precursors $(1-10$ $\mathrm{kb}$ ), called primary microRNAs or pri-miRNAs, that most frequently are synthesized by RNA pol II. Pri-miRNAs often encode more than one microRNA; thus, a microRNA can arise from a mono- or polycistronic primary transcript or can reside within the intron of a protein-coding gene transcript. The pri-miRNA is first reduced to a 60 - to 70-nucleotide-long pre-miRNA by the Microprocessor, a nuclear multiprotein complex that contains two essential components called Drosha and DGCR8/Pasha. After transit to the cytoplasm, escorted by the export receptor Exportin 5, the pre-miRNA is further processed to approximately 22-nucleotide mature microRNA(s) by Dicer, which-like Drosha - is a member of a superfamily of enzymes that recognize and cleave dsRNAs. One or both Dicer products are then bound (probably coordinately with cleavage) by an Ago family protein to form an active complex called RISC (for review, see Du and Zamore 2005; Kim 2005). Many additional proteins have been reported to be associated with mature microRNPs.

Narry Kim addressed the nuclear events in microRNA biogenesis by asking how the Microprocessor recognizes its substrates and how and when the Micro- 
processor cleaves intronic microRNAs (Han et al. 2006). Studies in her lab indicate that DGCR8 recognizes a ss-dsRNA junction within the pri-miRNA adjacent to the hairpin containing the mature microRNA sequence. The Microprocessor then measures about 11 bp along the duplex, thereby positioning the active site of Drosha to cleave both strands, staggered by $2 \mathrm{bp}$. This cleavage releases the pre-miRNA, ready for secondary processing by Dicer. The processing of intronencoded microRNAs results in production of both the microRNA and spliced mRNA. Brenda Bass discussed in more general terms the essential roles of dsRNAbinding proteins in assisting Drosha and Dicer cleavage, as well as in coordinating the progression of dsRNAs from one step to the next in the pathway of microRNA maturation (Parker et al. 2006).

The question of whether microRNAs are regulated posttranscriptionally was raised in several talks and posters. Scott Hammond's lab presented clear evidence that specific pri-miRNAs can be abundantly expressed in mammalian cells but not processed into mature microRNAs until a developmental signal releases the processing block (Thomson et al. 2006). Richard Carthew described the steps leading to RISC formation and the role of novel genes in inhibiting the production of RISC from small RNA precursors in cells of the Drosophila nervous system. Jim Dahlberg reported that the maturation of Xenopus oocytes produces a large increase in Dicer activity, indicating that microRNA biogenesis, in general, can be subject to developmental control.

Alex Schier showed that even within a developing embryo, abundantly expressed microRNAs can be prevented from acting within a privileged compartment. In zebra fish, miR-430 normally acts to promote degradation of maternal mRNAs (Giraldez et al. 2006). As expected, the maternally deposited nanos mRNA is targeted by miR-430 and destabilized in the soma. However, in the germ plasm, which is destined to become the germ line, nanos escapes the effects of miR430 (Mishima et al. 2006). It is not yet clear whether this is accomplished by affecting RISC biogenesis within the germ compartment, by preventing RISC action either in general or with a specific microRNA, or by protecting specific targets from microRNA-mediated repression.

\section{Key emerging questions:}

- How is the diversity of microRNA precursors recognized, leading to specificity in processing?

- How are pathways of microRNA biogenesis related in plants and animals?

- To what extent is the RNAi pathway as a whole regulated in given tissues and at specific points in development?

- What levels of control are exerted on the biogenesis of individual microRNAs?

- How is control of processing an individual microRNA exerted at the posttranscriptional level?

\section{The Structural Biology of RNA Silencing}

Understanding the mechanistic basis of RNA silencing pathways provides a special challenge for structural biology. In fact, the structures of full-length and subdomains of Ago and Dicer proteins that have currently been solved to high resolution are not those with wellcharacterized functions, but their homologs from singlecelled organisms - where it is not even clear that RNA interference pathways comparable to those in metazoans and plants exist.

Jennifer Doudna described the crystal structure of a Dicer enzyme from the parasite Giardia (Macrae et al. 2006). Members of the Dicer family endonucleolytically cleave dsRNAs into pieces ranging from 21 to 27 nucleotides and are critical for RNAi mediated by long dsRNAs, as well as for microRNA biogenesis. Giardia Dicer consists of two RNase III domains attached to a PAZ domain by a long $\alpha$-helix - which appears to be the measuring device-but it lacks the amino-terminal helicase and carboxy-terminal dsRBD found in Dicers from higher eukaryotes. The structure reveals a distinct kink in the connector helix and conformational flexibility, which may allow the processing of diverse premiRNA substrates. An attractive idea is that different Dicers produce slightly different-length pieces, thereby steering their products into different functional pathways by handing over the resulting siRNA duplexes to different Ago family proteins via interactions between their PAZ domains and the $3^{\prime}$ ends of the guide strands.

Three groups presented structures of Ago proteins, the core component of RISC, RITS, and perhaps other RNAi and microRNA effector complexes. Leemor Joshua-Tor recounted the seminal finding that the PIWI domain of Ago from Pyrococcus furiosus resembles RNase $\mathrm{H}$, indicating that Ago is the component of RISC and RITS responsible for the siRNA-directed "slicer" activity (Song et al. 2004). The structure of the PIWI domain of the archaeal Archaeoglobus fulgidus (Af) Ago protein complexed with a 16-nucleotide siRNA-like duplex, described by David Barford, has revealed a profound distortion of the $5^{\prime}$ end of the guide RNA strand and its binding to a pocket facilitated by metal ion contacts, suggesting that the PIWI domain also participates in RNA duplex unwinding and strand selection. Importantly, the residence of the $5^{\prime}$ nucleotide of the guide strand in a binding pocket within the PIWI domain may explain why the first nucleotide of siRNAs and microRNAs plays little role in selection of silencing targets by RISC (Parker et al. 2005). Dinshaw Patel discussed recognition of the siRNA duplex 3' overhang by the PAZ domains of both Dicer and Agol and what mutations tell us about the 5 '-phosphate-binding pocket of the PIWI domain of $A f$ Ago (Ma et al. 2004; Yuan et al. 2005, 2006). Clearly, future structures of siRNAs complexed with fulllength Dicer and Ago proteins from organisms with well-characterized RNAi pathways will be required to illuminate the molecular details of microRNA biogenesis and function. 


\section{Key emerging questions:}

- Will structures of Dicers and Argonautes that clearly participate in microRNA and siRNA pathways resemble those solved from model organisms?

- How do the dynamics of these proteins during small RNA biogenesis and effector functions relate to the static pictures presently available?

- Will structures of accessory factors such as DGCR8/Pasha reveal elements of substrate selection within microRNA biogenesis pathways?

\section{Translational Repression by MicroRNAs}

The precise mechanisms by which microRNAs regulate the expression of their mRNA targets remain to be resolved. However, some themes did begin to emerge at the meeting. Previous studies have indicated that microRNAs can act by mechanisms ranging from mRNA cleavage (prominent in plants but still rare in mammals) to mRNA sequestration to deadenylation to direct effects on mRNA translation via inhibition of initiation or elongation.

Alex Schier recounted the elegant finding that a particular microRNA, miR-430, is expressed at the onset of zygotic transcription during zebra fish embryogenesis and induces the decay of several hundred maternal mRNAs via rapid deadenylation (Giraldez et al. 2006). Jim Dahlberg described a similar role for the microRNA pathway in clearance of maternal mRNAs in Xenopus, suggesting that this may be a conserved function of the RNAi pathway in vertebrates. Deadenylation is not a secondary effect of lack of translation, and some 3'UTRs are more effective microRNA targets in one cell type than another, suggesting the existence of tissue-specific regulation by microRNAs.

In a similar vein, Witek Filipowicz reported that microRNA-induced repression of translation can be reversible (Bhattacharyya et al. 2006). In human hepatoma cells, miR-122 represses CAT-1 expression, with coincident localization of the cat-1 mRNA to processing bodies (P-bodies). By subjecting cells to stress conditions, repression of cat-1 can be relieved, with coincident exit of cat-1 from P-bodies. This correlates with recognition of an AU-rich element adjacent to the miRNA target site in the 3'UTR by an ARE-binding protein, HuR. Considered together with Alex Schier's report of cellular compartments in which mRNAs are protected from miRNA-mediated repression, a picture begins to emerge in which responses to microRNAs may be modulated dynamically. This fits well with the notion that 3'UTRs may integrate many cellular signals to determine both rates of mRNA translation and rates of mRNA decay.

Phil Sharp stressed observations that mRNAs being repressed by microRNAs are found on polysomes and that some reduction $(\sim 1.5$ - to 2 -fold $)$ in mRNA levels often accompanies repression (Petersen et al. 2006); experiments addressing whether microRNA-mediated translational repression is localized to specific cellular site(s) concluded that it occurs in the diffuse cytoplasm rather than necessarily in discrete foci such as P-bodies or stress granules (SGs) (Leung et al. 2006). Tim Nilsen reported an analysis of the subcellular distribution of microRNAs in actively growing HeLa cells and found the vast majority to be associated with polysomes, as was a down-regulated mRNA, solidifying evidence that elongation is a likely step at which microRNA-induced translation repression is achieved (Maroney et al. 2006).

Elisa Izaurralde provided evidence that microRNAs in Drosophila require AGO1 and the P-body component GW182 to achieve both translational repression and mRNA degradation, which occurs via deadenylation and decapping (Behm-Ansmant et al. 2006). Importantly, Izaurralde also shed light on why such disparate mechanistic explanations for microRNA-mediated repression may have emerged from studies in different laboratories. There are at least three discrete classes of targets in Drosophila: Some are down-regulated at the protein level in a manner that directly reflects changes at the mRNA level; some show no detectable change at the mRNA level yet have greatly decreased protein levels, suggesting regulation solely at the level of translation; and finally, some microRNA targets are repressed at the mRNA level but also to a much greater degree at the protein level. Repression of each of these classes showed differential degrees of dependence on RISC accessory factors such as GW182 and deadenylases.

Potential molecular mechanisms underlying translational modulation by microRNAs were suggested by two talks that provided insights into the activities of other translation components - the ribosome itself and poly(A)-binding protein (PABP), which functions as an initiation factor. Rachel Green presented biochemical evidence that the decoding center of the small ribosomal subunit undergoes substrate-specific switching between distinct structural states during peptide elongation and release (Cochella and Green 2005; Cochella et al. 2007). Nahum Sonenberg summarized the multifaceted roles of PABP-interacting proteins (Paips) in regulating initiation, the rate-limiting step in translation (Cho et al. 2005; Yoshida et al. 2006). Regardless of which step(s) ultimately emerges as the target of microRNP repression, it is further possible that the direction of effects on translation might differ under different cellular conditions (e.g., during development or dependent on the cell cycle), making control by microRNAs and their associated proteins even more versatile than previously imagined.

\section{Key emerging questions:}

- What is the mechanism by which microRNAs repress expression of their mRNA targets?

- Is there a single mechanism, or are different targets regulated differently?

- How common is dynamic regulation of microRNA-mediated repression?

- Do microRNAs integrate other signals to set the half-lives and translational efficacy of most cellular mRNAs? 


\section{Biological Functions of MicroRNAs}

Several speakers highlighted the complexity of microRNA-mediated impacts on developmental pathways and cell-fate decisions. Marja Timmermans and Scott Poethig discussed the roles of microRNAs and tasiRNAs in the specification of organ polarity and regulation of developmental timing in plants. The Timmermans lab had previously shown that a gradient of miR-166 emanating from the abaxial side of the incipient leaf restricts the expression of adaxial determinants (Juarez et al. 2004). Follow-up studies in the maize leafbladeless 1 mutant now reveal a role for tasiRNAs in the spatiotemporal regulation of miR-166. Cloning of leafbladeless 1, which is required for the specification of adaxial cell fate, revealed that it is the maize homolog of Arabidopsis suppressor of gene silencing 3 (SGS3), a key component of the tasiRNA pathway. Loss of leafbladeless 1 leads to mis-expression of miR-166, suggesting that in maize, leaf polarity is established by the opposing action of two distinct types of small regulatory RNAs.

Timmermans also raised the interesting possibility that microRNAs could be mobilized to create gradients of suppression in plant tissues. In many ways, this is similar to the well-established mobility of silencing signals induced by virus infection in plants and by feeding of dsRNAs to C. elegans. The mechanisms underlying systemic spreading of a silencing signal in C. elegans were discussed by Craig Hunter. SID1 and SID2 are both transmembrane proteins; SID1 is ubiquitously expressed whereas SID2 is primarily expressed in the intestinal lumen. Paralleling their expression patterns, SID1 is involved in intracellular transport (both import and export) of long dsRNA whereas SID2 is required for uptake of dsRNA from the gut (environmental RNAi defective)(Feinberg and Hunter 2003). The biological role of these proteins is still elusive, although current experiments are ongoing regarding a potential role in viral immunity.

Scott Poethig presented studies on the juvenile-to-adult transition in Arabidopsis, which is accelerated in zippy/ago 7, sgs3, and RNA-dependent RNA polymerase 6 (rdr6) mutants. These observations imply a role for RNAi in this transition. By identifying mRNAs whose abundance increases in these mutants, as well as through genetic hunts for second-site suppressors, the Poethig group identified key regulators of the transition, specifically the squamosa promoter binding protein-like family (SPL3/4/5) and the auxin-related genes ARF3 and ARF4 (Wu and Poethig 2006). The juvenile-to-adult transition is triggered when levels of SPL transcription factors increase in response to decreased levels of miR-156. ARF3 and ARF4 are targets of a tasiRNA (Hunter et al. 2006). Thus, multiple small RNA pathways converge to regulate the sensitivity of the phase-change mechanism to a temporal signal.

Oliver Hobert summarized his laboratory's work on microRNAs and gene regulatory circuits that control neuronal cell-fate specification in $C$. elegans. The interplay of microRNAs, lsy-6 and miR-273, and their respective target transcription factors, cog-1 and die-1, form a double-negative feedback loop that controls cell-fate specifi- cation in sensory neurons (Johnston et al. 2005, 2006). On the basis of this pathway, he advanced the idea that microRNAs can function as effective on-off switches in developmental decisions, as opposed to the more familiar perception of microRNAs as fine tuners of gene expression. Irene Bozzoni echoed this important concept in her talk on microRNAs expressed in hematopoiesis and leukemia. Here, $\mathrm{C} / \mathrm{EBP} \alpha$, a transcription factor regulating the miR-223 promoter, displaces a negative factor NFI-A, but miR-223 represses NFI-A, creating an autoregulatory loop that appears to control granulocytic differentiation (Fazi et al. 2005).

The roles of microRNAs in driving phenotypic variation, and ultimately evolution, were discussed by several investigators. In one very interesting example, Michel Georges described studies aimed at uncovering traits related to the exceptional meatiness (an economically important trait) of Texel sheep (Clop et al. 2006). Mapping of a QTL with large impact on muscle mass to the mysotatin gene revealed a $G$ to $A$ transition in the 3'UTR of myostatin. This change made myostatin a target for miR-1 and miR-206, both abundant microRNAs in skeletal muscle. Thus, the meatiness of Texel sheep is due to muscular hypertrophy associated with silencing of myostatin via the microRNA pathway. These results, and analysis of SNP databases, were used as support for the assertion that changes in microRNA-binding sites are an important underlying cause of phenotypic variation.

Ronald Plasterk discussed the identification of many microRNAs that are not conserved even among closely related species. In particular, certain microRNAs are found in humans but are absent from chimps (Berezikov et al. 2006). Thus, he asserted that changes in small RNA populations may help to drive adaptation on relatively short evolutionary timescales. Nikolaus Rajewsky provided support for evolutionary constraints on microRNA target sites by analyzing human SNP databases (Chen and Rajewsky 2006). He reported that negative selection is stronger on conserved predicted microRNA-binding sites in 3'UTRs than on other conserved sites. The data also predict the relevance of many non-conserved potential microRNA-binding sites, paralleling the assertions by Plasterk that small RNA regulatory pathways are a convenient way to drive evolutionary change.

Given the importance of microRNAs in nearly all aspects of cellular physiology and organismal development, it is not surprising that changes in microRNAs or their target sites are linked to disease. Frank Slack discussed the roles of microRNAs in human cancer, with a particular focus on let-7 as a noncoding tumor suppressor (Esquela-Kerscher et al. 2005; Johnson et al. 2005). Just as endogenous microRNAs can contribute to disease, it is evident that we can artificially harness the microRNA machinery to understand disease pathways. Indeed, Rene Bernards described efforts to use genome-wide, RNAibased genetic approaches to identify new cancer targets (Bernards et al. 2006; Brummelkamp et al. 2006). Extensive and community-based efforts, described by Norbert Perrimon, are also under way in Drosophila to understand the connectivity of genetic pathways in that model organism (Friedman and Perrimon 2006). 


\section{Key emerging questions:}

- Do microRNAs have conserved roles in regulating developmental transitions in plants and animals, and how does this relate to the convergent evolution of the microRNA pathway in these two kingdoms?

- Can microRNAs act as mobile signals, essentially behaving as morphogens?

- Is the interplay between small RNA pathways, e.g., microRNAs and tasiRNAs, unique to plants, or will similar interactions between small RNA classes be found in animals?

- What determines whether microRNAs act as rheostats or switches in gene expression pathways?

\section{CONCLUSIONS}

In retrospect, it was fitting that the 71 st Cold Spring Harbor Laboratory Symposium focused on Regulatory RNAs. As we complete this review of the work presented at the meeting, admittedly a bit tardily, Craig Mello and Andy Fire have just accepted the 2006 Nobel Prize in Physiology or Medicine. Their discovery of dsRNA-induced silencing in $C$. elegans has indeed seeded a new RNA revolution. The pervasive nature and practical utility of small RNA-driven regulatory processes has highlighted to the broader community the fundamental ways in which noncoding RNAs, small and large, are intertwined with virtually every cellular process.

\section{REFERENCES}

Alekseyenko A.A., Larschan E., Lai W.R., Park P.J., and Kuroda M.I. 2006. High-resolution ChIP-chip analysis reveals that the Drosophila MSL complex selectively identifies active genes on the male X chromosome. Genes Dev. 20: 848.

Aravin A., Gaidatzis D., Pfeffer S., Lagos-Quintana M., Landgraf P., Iovino N., Morris P., Brownstein M.J., Kuramochi-Miyagawa S., Nakano T., et al. 2006. A novel class of small RNAs bind to MILI protein in mouse testes. Nature 442: 203.

Bartel D.P. 2004. MicroRNAs: Genomics, biogenesis, mechanism, and function. Cell 116: 281.

Battle D.J., Lau C.K., Wan L., Deng H., Lotti F., and Dreyfuss G. 2006. The Gemin5 protein of the SMN complex identifies snRNAs. Mol. Cell 23: 273.

Behm-Ansmant I., Rehwinkel J., Doerks T., Stark A., Bork P., and Izaurralde E. 2006. mRNA degradation by miRNAs and GW182 requires both CCR4:NOT deadenylase and DCP1:DCP2 decapping complexes. Genes Dev. 20: 1885.

Berezikov E., Thuemmler F., van Laake L.W., Kondova I., Bontrop R., Cuppen E., and Plasterk R.H. 2006. Diversity of microRNAs in human and chimpanzee brain. Nat. Genet. 38: 1375.

Bernards R., Brummelkamp T.R., and Beijersbergen R.L. 2006. shRNA libraries and their use in cancer genetics. Nat. Methods 3: 701.

Bernstein E., Caudy A.A., Hammond S.M., and Hannon G.J. 2001. Role for a bidentate ribonuclease in the initiation step of RNA interference. Nature 409: 363.
Bertone P., Stolc V., Royce T.E., Rozowsky J.S., Urban A.E., Zhu X., Rinn J.L., Tongprasit W., Samanta M., Weissman S., et al. 2004. Global identification of human transcribed sequences with genome tiling arrays. Science 306: 2242.

Bhattacharyya S.N., Habermacher R., Martine U., Closs E.I., and Filipowicz W. 2006. Relief of microRNA-mediated translational repression in human cells subjected to stress. Cell 125: 1111.

Brummelkamp T.R., Fabius A.W., Mullenders J., Madiredjo M., Velds A., Kerkhoven R.M., Bernards R., and Beijersbergen R.L. 2006. An shRNA barcode screen provides insight into cancer cell vulnerability to MDM2 inhibitors. Nat. Chem. Biol. 2: 202.

Buhler M., Verdel A., and Moazed D. 2006. Tethering RITS to a nascent transcript initiates RNAi- and heterochromatindependent gene silencing. Cell 125: 873 .

Cai X., Schafer A., Lu S., Bilello J.P., Desrosiers R.C., Edwards R., Raab-Traub N., and Cullen B.R. 2006. Epstein-Barr virus microRNAs are evolutionarily conserved and differentially expressed. PLoS Pathog. 2: e23.

Carninci P., Kasukawa T., Katayama S., Gough J., Frith M.C., Maeda N., Oyama R., Ravasi T., Lenhard B., Wells C., et al. 2005. The transcriptional landscape of the mammalian genome. Science 309: 1559.

Chaumeil J., Le Baccon P., Wutz A., and Heard E. 2006. A novel role for Xist RNA in the formation of a repressive nuclear compartment into which genes are recruited when silenced. Genes Dev. 20: 2223.

Chen K. and Rajewsky N. 2006. Natural selection on human microRNA binding sites inferred from SNP data. Nat. Genet. 38: 1452 .

Cho P.F., Poulin F., Cho-Park Y.A., Cho-Park I.B., Chicoine J.D., Lasko P., and Sonenberg N. 2005. A new paradigm for translational control: Inhibition via $5^{\prime}-3^{\prime}$ mRNA tethering by Bicoid and the eIF4E cognate 4EHP. Cell 121: 411.

Clop A., Marcq F., Takeda H., Pirottin D., Tordoir X., Bibe B., Bouix J., Caiment F., Elsen J.M., Eychenne F., et al. 2006. A mutation creating a potential illegitimate microRNA target site in the myostatin gene affects muscularity in sheep. Nat. Genet. 38: 813.

Cochella L. and Green R. 2005. An active role for tRNA in decoding beyond codon:anticodon pairing. Science 308: 1178.

Cochella L., Brunelle J.L., and Green R. 2007. Mutational analysis reveals two independent molecular requirements during transfer RNA selection on the ribosome. Nat. Struct. Mol. Biol. 14: 30.

Conrad N.K., Mili S., Marshall E.L., Shu M.D., and Steitz J.A. 2006. Identification of a rapid mammalian deadenylationdependent decay pathway and its inhibition by a viral RNA element. Mol. Cell 24: 943.

Cromie M.J., Shi Y., Latifi T., and Groisman E.A. 2006. An RNA sensor for intracellular $\mathrm{Mg}(2+)$. Cell 125: 71.

Deng X. and Meller V.H. 2006. Non-coding RNA in fly dosage compensation. Trends Biochem. Sci. 31: 526.

Dowell R.D. and Eddy S.R. 2006. Efficient pairwise RNA structure prediction and alignment using sequence alignment constraints. BMC Bioinformatics 7: 400.

Du T. and Zamore P.D. 2005. microPrimer: The biogenesis and function of microRNA. Development 132: 4645.

Dye M.J., Gromak N., and Proudfoot N.J. 2006. Exon tethering in transcription by RNA polymerase II. Mol. Cell 21: 849 .

Emanuelsson O., Nagalakshmi U., Zheng D., Rozowsky J.S., Urban A.E., Du J., Lian Z., Stolc V., Weissman S., Snyder M., and Gerstein M. 2006. Assessing the performance of different high-density tiling microarray strategies for mapping transcribed regions of the human genome. Genome Res. (in press).

Esquela-Kerscher A., Johnson S.M., Bai L., Saito K., Partridge J., Reinert K.L., and Slack F.J. 2005. Post-embryonic expression of $C$. elegans microRNAs belonging to the lin-4 and let7 families in the hypodermis and the reproductive system. Dev. Dyn. 234: 868.

Fazi F., Rosa A., Fatica A., Gelmetti V., De Marchis M.L., Nervi C., and Bozzoni I. 2005. A minicircuitry comprised of microRNA-223 and transcription factors NFI-A and C/EBPalpha regulates human granulopoiesis. Cell 123: 819 . 
Feinberg E.H. and Hunter C.P. 2003. Transport of dsRNA into cells by the transmembrane protein SID-1. Science 301: 1545.

Fire A., Xu S., Montgomery M.K., Kostas S.A., Driver S.E., and Mello C.C. 1998. Potent and specific genetic interference by double-stranded RNA in Caenorhabditis elegans. Nature 391: 806 .

Friedman A. and Perrimon N. 2006. A functional RNAi screen for regulators of receptor tyrosine kinase and ERK signalling. Nature 444: 230.

Gendrel A.V. and Colot V. 2005. Arabidopsis epigenetics: When RNA meets chromatin. Curr. Opin. Plant Biol. 8: 142.

Gilbert S.D. and Batey R.T. 2006. Riboswitches: Fold and function. Chem. Biol. 13: 805.

Giraldez A.J., Mishima Y., Rihel J., Grocock R.J., Van Dongen S., Inoue K., Enright A.J., and Schier A.F. 2006. Zebrafish MiR-430 promotes deadenylation and clearance of maternal mRNAs. Science 312: 75 .

Girard A., Sachidanandam R., Hannon G.J., and Carmell M.A. 2006. A germline-specific class of small RNAs binds mammalian Piwi proteins. Nature 442: 199.

Golembe T.J., Yong J., and Dreyfuss G. 2005. Specific sequence features, recognized by the SMN complex, identify snRNAs and determine their fate as snRNPs. Mol. Cell. Biol. 25: 10989.

Gollnick P., Babitzke P., Antson A., and Yanofsky C. 2005. Complexity in regulation of tryptophan biosynthesis in Bacillus subtilis. Annu. Rev. Genet. 39: 47.

Gottesman S. 2005. Micros for microbes: Non-coding regulatory RNAs in bacteria. Trends Genet. 21: 399.

Grewal S.I. and Moazed D. 2003. Heterochromatin and epigenetic control of gene expression. Science 301: 798.

Grishok A., Pasquinelli A.E., Conte D., Li N., Parrish S., Ha I., Baillie D.L., Fire A., Ruvkun G., and Mello C.C. 2001. Genes and mechanisms related to RNA interference regulate expression of the small temporal RNAs that control C. elegans developmental timing. Cell 106: 23.

Gromak N., West S., and Proudfoot N.J. 2006. Pause sites promote transcriptional termination of mammalian RNA polymerase II. Mol. Cell. Biol. 26: 3986.

Grundy F.J. and Henkin T.M. 2006. From ribosome to riboswitch: Control of gene expression in bacteria by RNA structural rearrangements. Crit. Rev. Biochem. Mol. Biol. 41: 329.

Hamilton A.J. and Baulcombe D.C. 1999. A species of small antisense RNA in posttranscriptional gene silencing in plants. Science 286: 950.

Hammond S.M., Bernstein E., Beach D., and Hannon G.J. 2000. An RNA-directed nuclease mediates post-transcriptional gene silencing in Drosophila cells. Nature 404: 293.

Hammond S.M., Boettcher S., Caudy A.A., Kobayashi R., and Hannon G.J. 2001. Argonaute2, a link between genetic and biochemical analyses of RNAi. Science 293: 1146.

Han J., Lee Y., Yeom K.H., Nam J.W., Heo I., Rhee J.K., Sohn S.Y., Cho Y., Zhang B.T., and Kim V.N. 2006. Molecular basis for the recognition of primary microRNAs by the Drosha-DGCR8 complex. Cell 125: 887.

Hannon G.J. 2002. RNA interference. Nature 418: 244.

Hao L.Y., Armanios M., Strong M.A., Karim B., Feldser D.M., Huso D., and Greider C.W. 2005. Short telomeres, even in the presence of telomerase, limit tissue renewal capacity. Cell 123: 1121 .

Haussecker D. and Proudfoot N.J. 2005. Dicer-dependent turnover of intergenic transcripts from the human beta-globin gene cluster. Mol. Cell. Biol. 25: 9724.

Heard E. and Disteche C.M. 2006. Dosage compensation in mammals: Fine-tuning the expression of the $\mathrm{X}$ chromosome. Genes Dev. 20: 1848.

Hunter C., Willmann M.R., Wu G., Yoshikawa M., de la Luz Gutierrez-Nava M., and Poethig S.R. 2006. Trans-acting siRNA-mediated repression of ETTIN and ARF4 regulates heteroblasty in Arabidopsis. Development 133: 2973.

Hüttenhofer A. and Schattner P. 2006. The principles of guiding by RNA: Chimeric RNA-protein enzymes. Nat. Rev. Genet. 7: 475 .
Hutvagner G. and Zamore P.D. 2002. A microRNA in a multiple-turnover RNAi enzyme complex. Science 297: 2056.

Hutvagner G., McLachlan J., Pasquinelli A.E., Balint E., Tuschl T., and Zamore P.D. 2001. A cellular function for the RNAinterference enzyme Dicer in the maturation of the let-7 small temporal RNA. Science 293: 834

Irvine D.V., Zaratiegui M., Tolia N.H., Goto D.B., Chitwood D.H., Vaughn M.W., Joshua-Tor L., and Martienssen R.A. 2006. Argonaute slicing is required for heterochromatic silencing and spreading. Science 313: 1134.

Jacob F. and Monod J. 1961. Genetic regulatory mechanisms in the synthesis of proteins. J. Mol. Biol. 3: 318.

Jady B.E., Richard P., Bertrand E., and Kiss T. 2006. Cell cycledependent recruitment of telomerase RNA and Cajal bodies to human telomeres. Mol. Biol. Cell 17: 944.

Johnson S.M., Grosshans H., Shingara J., Byrom M., Jarvis R., Cheng A., Labourier E., Reinert K.L., Brown D., and Slack F.J. 2005. RAS is regulated by the let-7 microRNA family. Cell 120: 635.

Johnston R.J., Jr., Chang S., Etchberger J.F., Ortiz C.O., and Hobert O. 2005. MicroRNAs acting in a double-negative feedback loop to control a neuronal cell fate decision. Proc. Natl. Acad. Sci. 102: 12449.

Johnston R.J., Jr., Copeland J.W., Fasnacht M., Etchberger J.F., Liu J., Honig B., and Hobert O. 2006. An unusual Znfinger/FH2 domain protein controls a left/right asymmetric neuronal fate decision in C. elegans. Development 133: 3317.

Jopling C.L., Yi M., Lancaster A.M., Lemon S.M., and Sarnow P. 2005. Modulation of hepatitis C virus RNA abundance by a liver-specific MicroRNA. Science 309: 1577.

Juarez M.T., Kui J.S., Thomas J., Heller B.A., and Timmermans M.C. 2004. microRNA-mediated repression of rolled leaf1 specifies maize leaf polarity. Nature 428: 84.

Kanno T., Aufsatz W., Jaligot E., Mette M.F., Matzke M., and Matzke A.J. 2005a. A SNF2-like protein facilitates dynamic control of DNA methylation. EMBO Rep. 6: 649.

Kanno T., Huettel B., Mette M.F., Aufsatz W., Jaligot E., Daxinger L., Kreil D.P., Matzke M., and Matzke A.J. 2005b. Atypical RNA polymerase subunits required for RNAdirected DNA methylation. Nat. Genet. 37: 761.

Ketting R.F., Fischer S.E., Bernstein E., Sijen T., Hannon G.J., and Plasterk R.H. 2001. Dicer functions in RNA interference and in synthesis of small RNA involved in developmental timing in C. elegans. Genes Dev. 15: 2654.

Kim V.N. 2005. MicroRNA biogenesis: Coordinated cropping and dicing. Nat. Rev. Mol. Cell Biol. 6: 376.

Kishore S. and Stamm S. 2006. The snoRNA HBII-52 regulates alternative splicing of the serotonin receptor 2C. Science 311: 230.

Klattenhoff C., Bratu D.P., McGinnis-Schultz N., Koppetsch B.S., Cook H.A., and Theurkauf W.E. 2007. Drosophila rasiRNA pathway mutations disrupt embryonic axis specification through activation of an ATR/Chk2 DNA damage response. Dev. Cell 12: 45.

Knight S.W. and Bass B.L. 2001. A role for the RNase III enzyme DCR-1 in RNA interference and germ line development in Caenorhabditis elegans. Science 293: 2269.

Lagos-Quintana M., Rauhut R., Lendeckel W., and Tuschl T. 2001. Identification of novel genes coding for small expressed RNAs. Science 294: 853.

Lau N.C., Lim L.P., Weinstein E.G., and Bartel D.P. 2001. An abundant class of tiny RNAs with probable regulatory roles in Caenorhabditis elegans. Science 294: 858.

Lau N.C., Seto A.G., Kim J., Kuramochi-Miyagawa S., Nakano T., Bartel D.P., and Kingston R.E. 2006. Characterization of the piRNA complex from rat testes. Science 313: 363.

Lee R.C. and Ambros V. 2001. An extensive class of small RNAs in Caenorhabditis elegans. Science 294: 862.

Lee R.C., Feinbaum R.L., and Ambros V. 1993. The C. elegans heterochronic gene lin-4 encodes small RNAs with antisense complementarity to lin-14. Cell 75: 843 .

Leung A.K., Calabrese J.M., and Sharp P.A. 2006. Quantitative analysis of Argonaute protein reveals microRNA-dependent 
localization to stress granules. Proc. Natl. Acad. Sci. 103: 18125.

Li C.F., Pontes O., El-Shami M., Henderson I.R., Bernatavichute Y.V., Chan S.W., Lagrange T., Pikaard C.S., and Jacobsen S.E. 2006. An ARGONAUTE4-containing nuclear processing center colocalized with Cajal bodies in Arabidopsis thaliana. Cell 126: 93.

Li S., Crothers J., Haqq C.M., and Blackburn E.H. 2005. Cellular and gene expression responses involved in the rapid growth inhibition of human cancer cells by RNA interference-mediated depletion of telomerase RNA. J. Biol. Chem. 280: 23709.

Ma J.B., Ye K., and Patel D.J. 2004. Structural basis for overhang-specific small interfering RNA recognition by the PAZ domain. Nature 429: 318.

Macrae I.J., Zhou K., Li F., Repic A., Brooks A.N., Cande W.Z., Adams P.D., and Doudna J.A. 2006. Structural basis for double-stranded RNA processing by Dicer. Science 311: 195.

Majdalani N., Vanderpool C.K., and Gottesman S. 2005. Bacterial small RNA regulators. Crit. Rev. Biochem. Mol. Biol. 40: 93.

Manak J.R., Dike S., Sementchenko V., Kapranov P., Biemar F., Long J., Cheng J., Bell I., Ghosh S., Piccolboni A., and Gingeras T.R. 2006. Biological function of unannotated transcription during the early development of Drosophila melanogaster. Nat. Genet. 38: 1151

Maroney P.A., Yu Y., Fisher J., and Nilsen T.W. 2006. Evidence that microRNAs are associated with translating messenger RNAs in human cells. Nat. Struct. Mol. Biol. 13: 1102.

Martinez J., Patkaniowska A., Urlaub H., Luhrmann R., and Tuschl T. 2002. Single-stranded antisense siRNAs guide target RNA cleavage in RNAi. Cell 110: 563.

Matzke M.A. and Birchler J.A. 2005. RNAi-mediated pathways in the nucleus. Nat. Rev. Genet. 6: 24.

Meier U.T. 2005. The many facets of H/ACA ribonucleoproteins. Chromosoma 114: 1 .

. 2006. How a single protein complex accommodates many different H/ACA RNAs. Trends Biochem. Sci. 31: 311.

Mishima Y., Giraldez A.J., Takeda Y., Fujiwara T., Sakamoto H., Schier A.F., and Inoue K. 2006. Differential regulation of germline mRNAs in soma and germ cells by zebrafish miR430. Curr. Biol. 16: 2135.

Mochizuki K., Fine N.A., Fujisawa T., and Gorovsky M.A. 2002. Analysis of a piwi-related gene implicates small RNAs in genome rearrangement in tetrahymena. Cell 110: 689.

Moller T., Franch T., Hojrup P., Keene D.R., Bachinger H.P., Brennan R.G., and Valentin-Hansen P. 2002. Hfq: A bacterial Sm-like protein that mediates RNA-RNA interaction. Mol. Cell 9: 23 .

Montange R.K. and Batey R.T. 2006. Structure of the S-adenosylmethionine riboswitch regulatory mRNA element. Nature 441: 1172 .

Motamedi M.R., Verdel A., Colmenares S.U., Gerber S.A., Gygi S.P., and Moazed D. 2004. Two RNAi complexes, RITS and RDRC, physically interact and localize to noncoding centromeric RNAs. Cell 119: 789.

Nelson A.R., Henkin T.M., and Agris P.F. 2006. tRNA regulation of gene expression: Interactions of an mRNA $5^{\prime}$-UTR with a regulatory tRNA. RNA 12: 1254

Ngo H., Tschudi C., Gull K., and Ullu E. 1998. Double-stranded RNA induces mRNA degradation in Trypanosoma brucei. Proc. Natl. Acad. Sci. 95: 14687.

Nissen P., Hansen J., Ban N., Moore P.B., and Steitz T.A. 2000. The structural basis of ribosome activity in peptide bond synthesis. Science 289: 920.

Nosrati M., Li S., Bagheri S., Ginzinger D., Blackburn E.H., Debs R.J., and Kashani-Sabet M. 2004. Antitumor activity of systemically delivered ribozymes targeting murine telomerase RNA. Clin. Cancer Res. 10: 4983.

Parker G.S., Eckert D.M., and Bass B.L. 2006. RDE-4 preferentially binds long dsRNA and its dimerization is necessary for cleavage of dsRNA to siRNA. RNA 12: 807.

Parker J.S., Roe S.M., and Barford D. 2005. Structural insights into mRNA recognition from a PIWI domain-siRNA guide complex. Nature 434: 663.
Patel A.A. and Steitz J.A. 2003. Splicing double: Insights from the second spliceosome. Nat. Rev. Mol. Cell Biol. 4: 960.

Petersen C.P., Bordeleau M.E., Pelletier J., and Sharp P.A. 2006. Short RNAs repress translation after initiation in mammalian cells. Mol. Cell 21: 533 .

Pontes O., Li C.F., Nunes P.C., Haag J., Ream T., Vitins A., Jacobsen S.E., and Pikaard C.S. 2006. The Arabidopsis chromatin-modifying nuclear siRNA pathway involves a nucleolar RNA processing center. Cell 126: 79.

Prasanth K.V., Prasanth S.G., Xuan Z., Hearn S., Freier S.M., Bennett C.F., Zhang M.Q., and Spector D.L. 2005. Regulating gene expression through RNA nuclear retention. Cell 123: 249 .

Qi Y., He X., Wang X.J., Kohany O., Jurka J., and Hannon G.J. 2006. Distinct catalytic and non-catalytic roles of ARGONAUTE4 in RNA-directed DNA methylation. Nature 443: 1008.

Rea S. and Akhtar A. 2006. MSL proteins and the regulation of gene expression. Curr. Top. Microbiol. Immunol. 310: 117.

Ruby J.G., Jan C., Player C., Axtell M.J., Lee W., Nusbaum C., Ge H., and Bartel D.P. 2006. Large-scale sequencing reveals 21U-RNAs and additional microRNAs and endogenous siRNAs in C. elegans. Cell 127: 1193.

Song J.J., Smith S.K., Hannon G.J., and Joshua-Tor L. 2004. Crystal structure of Argonaute and its implications for RISC slicer activity. Science 305: 1434.

Stein A.J., Fuchs G., Fu C., Wolin S.L., and Reinisch K.M. 2005. Structural insights into RNA quality control: The Ro autoantigen binds misfolded RNAs via its central cavity. Cell 121: 529.

Storz G., Altuvia S., and Wassarman K.M. 2005. An abundance of RNA regulators. Annu. Rev. Biochem. 74: 199.

Storz G., Opdyke J.A., and Zhang A. 2004. Controlling mRNA stability and translation with small, noncoding RNAs. Curr. Opin. Microbiol. 7: 140.

Sullivan C.S., Grundhoff A.T., Tevethia S., Pipas J.M., and Ganem D. 2005. SV40-encoded microRNAs regulate viral gene expression and reduce susceptibility to cytotoxic T cells. Nature 435: 682.

Thomson J.M., Newman M., Parker J.S., Morin-Kensicki E.M., Wright T., and Hammond S.M. 2006. Extensive post-transcriptional regulation of microRNAs and its implications for cancer. Genes Dev. 20: 2202.

Tomlinson R.L., Ziegler T.D., Supakorndej T., Terns R.M., and Terns M.P. 2006. Cell cycle-regulated trafficking of human telomerase to telomeres. Mol. Biol. Cell 17: 955.

Ule J., Stefani G., Mele A., Ruggiu M., Wang X., Taneri B., Gaasterland T., Blencowe B.J., and Darnell R.B. 2006. An RNA map predicting Nova-dependent splicing regulation. Nature 444: 580.

Vagin V.V., Sigova A., Li C., Seitz H., Gvozdev V., and Zamore P.D. 2006. A distinct small RNA pathway silences selfish genetic elements in the germline. Science 313: 320.

Valencia-Sanchez M.A., Liu J., Hannon G.J., and Parker R. 2006. Control of translation and mRNA degradation by miRNAs and siRNAs. Genes Dev. 20: 515.

Verdel A., Jia S., Gerber S., Sugiyama T., Gygi S., Grewal S.I., and Moazed D. 2004. RNAi-mediated targeting of heterochromatin by the RITS complex. Science 303: 672 .

Weisblum B. 1995. Erythromycin resistance by ribosome modification. Antimicrob. Agents Chemother. 39: 577.

West S., Gromak N., and Proudfoot N.J. 2004. Human 5' $\rightarrow$ 3' exonuclease Xrn2 promotes transcription termination at cotranscriptional cleavage sites. Nature 432: 522

West S., Gromak N., Norbury C.J., and Proudfoot N.J. 2006. Adenylation and exosome-mediated degradation of cotranscriptionally cleaved pre-messenger RNA in human cells. Mol. Cell 21: 437.

Wightman B., Ha I., and Ruvkun G. 1993. Posttranscriptional regulation of the heterochronic gene lin-14 by lin- 4 mediates temporal pattern formation in C. elegans. Cell 75: 855 .

Will C.L. and Luhrmann R. 2005. Splicing of a rare class of introns by the U12-dependent spliceosome. Biol. Chem. 386: 713 . 


\section{HANNON ET AL.}

Winkler W.C. 2005. Riboswitches and the role of noncoding RNAs in bacterial metabolic control. Curr. Opin. Chem. Biol. 9: 594.

Wu G. and Poethig R.S. 2006. Temporal regulation of shoot development in Arabidopsis thaliana by miR156 and its target SPL3. Development 133: 3539.

Xu N., Tsai C.L., and Lee J.T. 2006. Transient homologous chromosome pairing marks the onset of $\mathrm{X}$ inactivation. Science 311: 1149 .

Yik J.H., Chen R., Nishimura R., Jennings J.L., Link A.J., and Zhou Q. 2003. Inhibition of P-TEFb (CDK9/Cyclin T) kinase and RNA polymerase II transcription by the coordinated actions of HEXIM1 and 7SK snRNA. Mol. Cell 12: 971.

Yoshida M., Yoshida K., Kozlov G., Lim N.S., De Crescenzo G., Pang Z., Berlanga J.J., Kahvejian A., Gehring K., Wing S.S., and Sonenberg N. 2006. Poly(A) binding protein (PABP) homeostasis is mediated by the stability of its inhibitor, Paip2. EMBO J. 25: 1934.

Yuan Y.R., Pei Y., Chen H.Y., Tuschl T., and Patel D.J. 2006. A potential protein-RNA recognition event along the RISC- loading pathway from the structure of A. aeolicus argonaute with externally bound siRNA. Structure 14: 1557.

Yuan Y.R., Pei Y., Ma J.B., Kuryavyi V., Zhadina M., Meister G., Chen H.Y., Dauter Z., Tuschl T., and Patel D.J. 2005. Crystal structure of $A$. aeolicus argonaute, a site-specific DNA-guided endoribonuclease, provides insights into RISCmediated mRNA cleavage. Mol. Cell 19: 405.

Zamore P.D., Tuschl T., Sharp P.A., and Bartel D.P. 2000. RNAi: Double-stranded RNA directs the ATP-dependent cleavage of mRNA at 21 to 23 nucleotide intervals. Cell 101: 25.

Zappulla D.C. and Cech T.R. 2004. Yeast telomerase RNA: A flexible scaffold for protein subunits. Proc. Natl. Acad. Sci. 101: 10024

Zappulla D.C., Goodrich K., and Cech T.R. 2005. A miniature yeast telomerase RNA functions in vivo and reconstitutes activity in vitro. Nat. Struct. Mol. Biol. 12: 1072.

Zhang A., Wassarman K.M., Ortega J., Steven A.C., and Storz G. 2002. The Sm-like Hfq protein increases OxyS RNA interaction with target mRNAs. Mol. Cell 9: 11 . 


\section{$\$_{\text {SSH }}^{\infty}$ \& Cold Spring Harbor Symposia SYMPOSIA}

\section{The Expanding Universe of Noncoding RNAs}

G.J. HANNON, F.V. RIVAS, E.P. MURCHISON, et al.

Cold Spring Harb Symp Quant Biol 2006 71: 551-564

Access the most recent version at doi:10.1101/sqb.2006.71.064

References This article cites 131 articles, 50 of which can be accessed free at: http://symposium.cshlp.org/content/71/551.full.htmI\#ref-list-1

\section{License}

Email Alerting Receive free email alerts when new articles cite this article - sign up in Service the box at the top right corner of the article or click here. 